\title{
Deans, Decisions, Data
}

Danny Anderson, Dean, College of Liberal Arts and Sciences, University of Kansas

s deans, we seek to make good, indeed excellent, decisions. We strive to lead
with intentionality, exercise influence, and increasingly we turn to data to in-
form our decisions. Drawing upon my experience as the dean of the College of Liberal Arts and Sciences at the University of Kansas, my goal is to present five key strategies that have aided me in the use of data for decision-making as well as for capacity-building.

At the start of the twenty-first century, financial constraints shape our choices. At the same time, technology allows us to access abundant data. This context of financial constraint and data abundance-the age of "big data" means that we use data to gain actionable insights during a time of uncertainty about the future of higher education. Last year in this forum Steve Warren noted the future-oriented quality of our decisions as university leaders; quoting professional hockey star Wayne Gretsky, he emphasized that our goal is "to play to where the puck is going to be" (33). Viewing data with this predictive purpose places deans' decisions clearly within the realm of analytics. Drawing upon a survey of Chief Information Officers, Jacqueline Bischel defines analytics as "the use of data, statistical analysis, and explanatory and predictive models to gain insights and act on complex issues." (6) As Bischel's definition makes clear, data and action are linked. (Warren's contribution in this volume explores another sport analogy also related to analytics: the "sabrmetrics" created by Bill
James that optimizes decisions in baseball economics, a veritable revolution recounted in Michael Lewis's Moneyball: The Art of Winning an Unfair Game. In an era of financial constraints, we all may feel like we're in an unfair game. This is all the more reason for making certain that our decision-making strategies position us to win.)

With these concepts in mind, I propose here some suggestions to guide in the use of data for decision-making in the context of a distributed authority model, which is characteristic of a large public research university. These recommendations emerge from my experience implementing Academic Analytics in a College-wide process in academic year 20122013. Academic Analytics is a proprietary database that requires an institutional contract and an individually signed confidentiality agreement; authorized users agree to limit the reproduction of information from the dataset and acknowledge the database as "trade secret" intellectual property. While these practices and lessons learned have emerged from work with Academic Analytics, the recommendations can guide in 
the collective use of a variety of datasets for the purpose of shared decision-making.

\section{Five Strategies}

First, engage department chairs. They are closer to faculty members and students, and they know nuances that may not be immediately apparent to others. As Allan Tucker notes in Chairing the Academic Department, "A brilliant university or college administration with inept chairpersons cannot survive; an inept administration, with the help of a group of brilliant chairpersons, usually can" (32). By drawing upon the strengths and insights of the department chairs, decisions can be more effective, generate buy-in at all levels, and avoid some pitfalls. Remember too that department chairs have their own "day jobs" being chairs, so as deans we need to break large datasets into manageable "chunks" directly related to the decisions at hand. While analysis for the sake of analysis may be intellectually invigorating, linking the data to a decision point looming on the academic calendar can build momentum and shared purpose.

Second, contextualize the datasets with a variety of institutional research information. Sometimes the unusual detail in one dataset or the anomaly in another is linked to historical changes, policy changes, or personnel practices, to suggest a few possibilities, and the juxtaposition of multiple, related datasets can help draw out these connections. We can strive to optimize teaching load, space allocation, research funds, or leadership succession in isolation, but when we bring these topics together around an academic mission, we achieve real benefits.
Similarly, as we strive to skate to where the puck is going to be, we must draw upon historical information about institutional strengths and areas where we may be poised to achieve greater prominence. Keeping these various contextual horizons in sight will ensure that we use the data more effectively and develop the best strategies for realizing our goals.

Third, make conversations with department chairs and faculty central in the task of understanding complex data and building a shared vision for the future. Chair engagement and contextual information both emerge through collaborative examination of the data. This strategy is essential for owning the process of change. As librarian Brian Mathews writes in his blog "The Ubiquitous Librarian": "I keep getting distracted by our profession's desire for change to be data-driven. I prefer change to be human-driven. I'd much rather enable people to become more successful rather than focusing on making the numbers look better. [...] What do we want/need to know to enact change? Or taken further - to foster innovation?" Having conversations with department chairs reminds us that change is "humandriven."

Fourth, take a deep breath and be prepared to state repeatedly: data informs the decisions we make; data will not make the decisions for us. The phrase "data driven," as Brian Mathews points out, often creates confusion. Oxford faculty member Viktor MayerSchonberger and data editor Kenneth Cukier for The Economist, in Big Data: A Revolution that Will Transform How We Live, Work, and Think, take the point a step 
further and contend that the human element is essential: "What is greatest about human beings is precisely what the algorithms and silicon chips don't reveal, what they can't reveal because it can't be captured in data. It is not the 'what is,' but the 'what is not': the empty space, the cracks in the sidewalk, the unspoken and the not-yet-thought." They go on to note that the human ability to discern "what the data does not say" is "the spark of invention." As we think about decisions and data for making change, MayerSchonberger and Cukier contend that, "In a world of big data, it is our most human traits that will need to be fosteredour creativity, intuition, and intellectual ambition-since our ingenuity is the source of our progress" (196-97).

Fifth, as we emphasize engagement, context, conversation, and human traits, we can begin to see that data are narratives waiting to be told. Each dataset represents the human reality of our students, staff, and faculty. Often described as productivity, ranking, stature, cost, retention, or target, these data points are disembodied, aggregated stand-ins for individuals. We need to be able to tell our various audiences persuasive stories about the accomplishments and challenges, the dreams and struggles of the students, staff, and faculty in our universities. And if we have to go deep into the numbers when telling the story, besides the human faces we portray, we also need to make use of data visualization strategies that promote deep understanding as our audiences rapidly interpret complex statistical information.

\section{Challenges to Consider}

The conversation to gain maximum insights from Academic Analytics as well as from other datasets at the University of Kansas is still underway. There is not a single decision to be made, but rather a cascade of continuing and linked decisions as we chart our path. The collaborations built with these strategies have helped when we hit bumps, so it may also be useful to consider some of the challenges associated with the rapid introduction of new kinds of data as well as the anxiety provoked by the high stakes questions regarding the future of higher education.

On the one hand, there are reservations and resistances that emerge from the use of data for informing decisions. There are concerns about the accuracy and integrity of the data as well as about the justification for reducing complex phenomena to numbers, such as a single "productivity index." Others point out the potential for misusing or distorting the data, especially by taking it out of context. There is a clear worry about data-usage as a surveillance tool that violates individual privacy or erodes academic freedom. Following on this line of thinking, others perceive the usage of data as a threat to shared faculty governance when university administrators have confidential access to proprietary, trade secret information about individual faculty productivity and performance. All of these topics are worthy of attention in the conversation and create our common ground for moving forward.

Proprietary data intermediaries, like Academic Analytics, are emergingthere will be more. They aggregate public 
data and sell access to the dataset back to universities and colleges. These data intermediaries all purportedly help us set better departmental goals, mentor faculty, establish hiring priorities, make retention offer decisions, and select key areas of strength for continuing university investment. Similarly, for most of us our institutional data can be used to identify bright spots in teaching success and generate new data for the emerging field of learning analytics. Joe Steinmetz provides a broad-ranging characterization of analytics in the contemporary university in order to underscore that data provide us with new ways to map our intellectual communities in order to identify the patterns of success for research as well as instruction. Mardy Eimers takes my focus on recommendations a step further, and contemplates the potential need for institutional policy. And Gary Allen contends that the age of big data and analytics in the university means a behind-the-scenes revolution in the architecture of our technology infrastructure that includes a wide range of issues: system records and data standards, sustainable financial models and security, storage and speed of your connection or your processor. In short, even as Michael O'Brien sounds a healthy reminder that the current focus on "big data" may correspond to crowd behavior more than rational choice, as university leaders we should expect our need to work with data to intensify in the immediate future. Having a good game plan is essential.

\section{Proceed with Care}

Deans in the twenty-first century operate in a decision-making environment that combines traits set forth in two books. On the one hand, the scholar of educational leadership, Robert Birnbaum, in 1988 captured many of our current conditions in his classic work, How Colleges Work: The Cybernetics of Academics Organization and Leadership. Birnbaum associates the use of data with the bureaucratic aspect of the contemporary university and he questions the degree to which data informs decisions. Instead, he suggests that leaders may roll out data as a symbolic action designed to legitimize decisions that are already made. In essence, the use of data may be ritualistic, meant more for show than substance (7879).

On the other hand, Big Data: A Revolution that Will Transform How We Live, Work, and Think provides an entirely different view. Authors Mayer-Schonberger and Cukier emphasize the new science emerging around big data that combines multiple datasets to identify actionable correlations. Such information provides a new social infrastructure and mental outlook for decision-making. Whereas Birnbaum suggests that data in universities has often served more to confirm decisions, Mayer-Schonberger and Cukier contend that big data can inform predictive modeling in new and unexpected ways. As you read the following comment from Big Data, recall that today we commonly describe colleges, universities, and higher education as an industry that is accountable for public transparency, efficiency in operations, and effectiveness in research and instruction: "As big data becomes a source of competitive advantage for many companies, the structure of entire industries will be reshaped. 
The rewards, however, will accrue unequally. And the winners will be found among large and small firms, squeezing out the mass in the middle" (MayerSchonberger and Cukier, 145). Deans likely feel pressures to gain advantage for their college or school within the university, even while seeking to collaborate with fellow deans. And deans, provosts, and presidents undeniably feel pressures to position their universities for success in an era of scarce resources, increased public calls for accountability, and rising competition for students and federally sponsored research. Whereas we all may recognize the data use that Birnbaum describes as ritualistic, today we all strive to adopt a predictive analytics mindset as we imagine our possible futures.

University leaders need to develop a coherent strategy for the effective use of data within their institutional contexts. Two clear lessons stand out for me. First, we must be clear about our responsibility to use tools wisely to inform our decision making. We cannot and should not abdicate our judgment, authority, or responsibility to datasets. As Mayer-Schonberger and Cukier note, "Big data is a resource and a tool. It is meant to inform, rather than explain; it points us toward understanding, but it can still lead to misunderstanding, depending on how well or poorly it is wielded. And however dazzling we find the power of big data to be, we must never let its seductive glimmer blind us to its inherent imperfections" (197). And as Susan Kemper reminds us, we must be aware of the seduction of confirmation bias that only trots out the numbers that cook the books the way we want to read them. There are promises and there are perils in the way we make use of data.

Second, datasets and decisions are punctuation points that bring to predication the changes we strive to enact. To be successful, to have influence, and to motivate campus communities, we must develop strategies for working on multiple organizational levels. As Lee G. Bolman and Terrence E. Deal write in their classic textbook, Reframing Organizations: Artistry, Choice, and Leadership: "Modern organizations often rely too much on engineering and too little on art in their search for attributes like quality, commitment, and creativity. Art is not a replacement for engineering but an enhancement. Artistic leaders and managers help us see beyond today's reality to forms that release untapped individual energies and improve collective performance. The leader as artist relies on images as well as memos, poetry as well as policy, reflection as well as command, and reframing as well as refitting" (17). Data and analytics as well as engagement, context, conversation, judgment, and narratives can all be brought together to help us map our way forward and release the energies we need to construct our future.

\section{Works Cited}

Birnbaum, Robert. How Colleges Work: The Cybernetics of Academic Organization and Leadership. San Francisco: JoseeyBass Publishers, 1988.

Bischel, Jacqueline. "Analytics in Higher Education: Benefits, Barriers, Progress, and Recommendations." Research Report. Louisville, Colorado: EDUCAUSE Center for Applied Research, August 2012. http://www.educause.edu/ecar. Mathews, Brian. "Data-Driven DecisionMaking vs. Discovery-Driven Planning 
(don't measure a butterfly using the metrics of a caterpillar)." The Ubiquitous Librarian. The Chronicle of Higher Education. Blog post July 23, 2012.

Mayer-Schonberger, Viktor and Kenneth Cukier. Big Data: A Revolution that Will Transform How We Live, Work, and Think. Boston: Houghton Mifflin Harcourt, 2013. Tucker, Allan. Chairing the Academic Department: Leadership Among Peers. Phoenix:
American Council on Education/Oryx Press, 1993.

Warren, Steven. "Skating to Where the Puck is Going to Be." Information Systems as Infrastructure for University Research Now and in the Future. Lawrence, Kansas: Merrill Advance Studies Center Report, 2012. 